\title{
DESTILAÇÃO VIRTUAL DO VINHO COMO INSTRUMENTO REAL DE ENSINO APRENDIZAGEM DE QUÍMICA
}

\author{
VIRTUAL DISTILLATION OF WINE AS A REAL INSTRUMENT OF TEACHING \\ CHEMISTRY LEARNING
}

\section{DESTILACIÓN VIRTUAL DEL VINO COMO INSTRUMENTO REAL DE ENSEÑANZA APRENDIZAJE DE QUÍMICA}

\author{
Eloísa Vieira*,** \\ eloisavieiracn@hotmail.com \\ Denise Celeste Godoy ** \\ denise.cgar@gmail.com \\ Hérica Cambraia Gomes ***, **** \\ hericacambraia@gmail.com
}

\section{Resumo}

Esse trabalho relata os resultados de uma prática virtual sobre destilação do vinho, aplicado a uma turma de alunos do primeiro ano do Ensino Médio da escola pública estadual Pereira Ignácio, através de testes de sondagem (pré-testes e pós-testes). Os resultados desse estudo mostraram que houve evolução nos conceitos dos alunos sobre a destilação. Com isso, podemos inferir que a aula prática virtual de destilação do vinho poder-se-á colaborar como uma importante ferramenta para o professor, podendo propiciar aos estudantes uma melhor assimilação dos conteúdos, contribuindo assim para o ensino de Química.

Palavras-Chave: Ensino de Química; aula prática virtual; destilação do vinho.

\begin{abstract}
This work reports the results of a virtual practice on wine distillation, applied to a group of first year students of the public school Pereira Ignácio, through pre-tests and post-tests, . The results of this study showed that there was an evolution in students' concepts about distillation. With this, we can infer that the virtual practical class of wine distillation can collaborate as an important tool for the teacher, being able to provide students with a better assimilation of the contents, thus contributing to the teaching of Chemistry.
\end{abstract}

Keywords: Teaching Chemistry; virtual classroom practice; distillation of wine.

\section{Resumen}

Este trabajo relata los resultados de una práctica virtual sobre destilación del vino, aplicado a una clase de alumnos del primer año de la Enseñanza Media de la escuela pública estatal Pereira Ignacio, a través de pruebas de sondeo (pre-pruebas y post-tests). Los resultados de este estudio mostraron que hubo cambios en los conceptos de los alumnos sobre la destilación. Con ello, podemos inferir que la clase práctica virtual de destilación del vino se podrá colaborar como una importante herramienta para el profesor, pudiendo propiciar a los estudiantes una mejor asimilación de los contenidos, contribuyendo así a la enseñanza de Química.

Palabras clave: Enseñanza de Química; clase práctica virtual; destilación del vino. 


\section{INTRODUÇÃO}

Um dos desafios no ensino de Química é aliar o conhecimento escolar e os alunos e nesse sentido a maioria das instituições educacionais que possuem a disciplina de Química no seu currículo escolar tem passado por grandes problemas no decorrer dos anos, pois os alunos não têm uma visão adequada dessa disciplina (RODRIGUES, 2009).

O distanciamento existente entre os conteúdos expostos na sala de aula e a vivência dos alunos, tanto como a demonstração da realidade dos profissionais de química impede o contato dos alunos com a cultura científica, pois há apenas a tentativa de transferências de conteúdos, ausente dos pensamentos científico e crítico (RODRIGUES, 2009).

De acordo com Demo (1996) em vez do ritual expositivo docente e da passividade discente, busca-se criar um espaço e um momento de trabalho conjunto, no qual todos são atores, colaborando para um objetivo compartido.

Freqüentemente é feito um questionamento por parte dos alunos acerca do motivo pelo qual estuda química, visto que nem sempre este conhecimento será necessário na futura profissão (RODRIGUES et. al., 2000).

Nessa perspectiva, a inclusão das aulas práticas pode contribuir e muito no aprendizado dos alunos, pois, o laboratório tem um papel central no ensino de química e as pesquisas têm revelado a sua importância no engajamento dos estudantes no processo de investigação, articulando o trabalho experimental à resolução de problemas semiabertos podendo ser muito eficaz para a aprendizagem de conceitos, procedimentos e atitudes pelos estudantes (GOI E SANTOS, 2008), além de propiciar uma sólida construção do conhecimento pelo aluno e mostrar a relação interdisciplinar da Química com as demais ciências (SCHNETZLER op.cit., 1995).

O laboratório constitui-se em um ambiente de aprendizagem significativo no que se refere à capacidade do aluno em associar assuntos relacionados à teoria presente nos livros didáticos, pela realização de experiências, sendo um local de mudanças no ambiente de aprendizagem da sala de aula, permitindo ao aluno visualizar a teoria da sala de aula de forma dinâmica, vivenciando a teoria dos livros didáticos por meio da experimentação. 
A maioria dos professores concorda com a importância das aulas de laboratório no processo ensino-aprendizagem, acreditando ser uma forma de tanto motivar e estimular os alunos a assistirem às aulas, como também ser

uma maneira mais prática e fácil deles relacionarem os conceitos vistos em sala de aula com situações do seu dia a dia (LIMA, 2004 apud CAVALCANTE; SILVA, 2008).

Apesar da contribuição das atividades práticas na aprendizagem, nem sempre é possível a realização de experimentos, pois falta de materiais, muito conteúdo e pouco tempo e grande quantidade de alunos por turma. (SILVA E ZANOM, 2000; BUENO E KOVALICZN, 2008; PESSOA et al, 1995; BORGES, 2002; KRASILCHIK, 2005; KANBACH et al, 2005; MAMPRIN et al, 2007),

muitas escolas não têm laboratório e, quando isso acontece, faltam-lhe vidrarias, reagentes, professor laboratorista ou formação suficiente do professor para ministrar aulas em laboratório (NARDI,1998). Para Nardi (1998), os professores alegam que não realizam experimentos por possuírem um número excessivo de aulas, não tendo tempo de preparar aulas específicas de laboratório, além do número elevado de alunos por turma.

Em adição, a ausência do professor laboratorista colabora para a não realização das aulas práticas, visto que a preparação e a condução das mesmas são trabalhosas, pois, para a realização de uma aula prática, além de ser necessária a feitura de um roteiro e a elaboração de um relatório, tem-se que montar bancadas com os reagentes e vidrarias necessários para a realização do experimento. E mais: assim que a aula for ministrada, faz-se necessário desmontá-la, descartarem-se os reagentes, ser lavado, secado e guardado todo o material que foi utilizado (Vieira, 2011).

Mesmo que o contexto seja favorável para a prática de atividades experimentais os professores alegam sempre que está faltando alguma coisa (MAMPRIN, et al, 2007), justificando a e buscam reforçar a carência ou a deficiência de algo para justificar a aversão às atividades experimentais.

Penteado e Kovaliczn (2008) propõem em seu trabalho "Importância de materiais de laboratório para ensinar Ciências", diversas possibilidades de se desenvolver junto aos alunos atividades que contemplam a prática nas aulas de ciências de forma interativa e de fácil execução, o que permite ao professor desenvolver criativamente novas formas de ensinar e aprender Ciências. 
Nesse trabalho apresentamos uma pesquisa sobre aprendizagem dos alunos acerca da destilação do vinho, através de um laboratório virtual, onde exploramos os conhecimentos do cotidiano dos estudantes e o integramos no currículo em diferentes momentos dos processo de ensino e de aprendizagem pois, muitas vezes o estudante não estabelece relação do conhecimento cotidiano com o científico, e nesse sentido Mêndez (2004) nos diz que:

\footnotetext{
"Introduzindo elementos cotidianos em nossas classes, o aluno tomará consciência de que existem diferentes formas de analisar a realidade, a cotidiana e a científica, que não se contradizem e sim que se completam, e que é possível a transferência entre ambos domínios" (Méndez, 2004, p. 111).
}

\section{A IMPORTÂNCIA DOS LABORATÓRIOS VIRTUAIS}

De acordo com Trindade e cols., (1996), a Realidade Virtual baseia-se na construção computacional de ambientes gráficos tridimensionais. Por meio de hardware específico, consegue-se em tempo real a interação e manipulação dos objetos desses cenários, numa completa imersão num mundo "alternativo". Carnevale e colaboradores (2003) e Yamamoto e colaboradores (2001), definem o Laboratório Virtual (LV) como um programa de Informática que simula atividades práticas, desenvolvidas em laboratórios.

Segundo Fadul, 1982, a criação dos laboratórios virtuais surgiu da necessidade do uso dos laboratórios em tempo real, ou seja,com acesso a qualquer hora do dia e por um grande número de pessoas, já que um único experimento pode ser compartilhado por dezenas de pessoas, estando elas na mesma cidade ou geograficamente dispersas, além da questão dos custos na utilização de um laboratório real que torna em muitos casos bastante oneroso para as empresas ou instituições

De acordo com Oliveira et.al., (2005) a realidade virtual colabora muito com a educação devido as suas características de criar sensações de realidade como a Realidade virtual tem muito a oferecer na área educacional devido as suas características que criam uma sensação de realidade. Essas características são a imersão, a interação e a navegação. Dessa forma, o aluno explora um assunto de forma interativa e aprende a partir de sua imersão no próprio contexto deste assunto. Ainda, nesta pesquisa o autor 
destaca algumas razões em que os ambientes virtuais podem contribuir no ensino, como, tornar o ambiente mais divertido e interessante, assim como, possibilitar as pessoas com necessidades especiais realizem tarefas que de outra forma não seriam possíveis. Também salienta que o ambiente virtual reduz o custo na realização de experimentos que muitas vezes necessitam de investimentos financeiros, além de realizar atividades impossíveis de serem realizadas no mundo real, como a visualização de moléculas. Em adição, os ambientes virtuais oportuniza inovações e criação de experimentos e elimina o risco de acidentes com substâncias químicas.

Mas Freinet, (1997) adverte que "os laboratórios virtuais são bons para assimilar a teoria, mas não substituem processos reais, seu modelo é apenas uma aproximação que não pode reproduzir todos os aspectos do processo" também não permite que novos resultados possam ser descobertos, já que todas as experiências são previamente programadas para serem executadas do mesmo modo, e os resultados serão sempre os mesmos..

Carnevale e colaboradores (2003) e Yamamoto e colaboradores (2001), listaram as vantagens e desvantagens de um laboratório virtual. Apontaram como vantagem do laboratório virtual de Física e Química o fato de realizar experimentos que só seriam viáveis em laboratórios muito bem equipados. A realização de experimentos com reagentes tóxicos também seria impensável num laboratório real. Ressaltam ainda que o laboratório virtual possibilita uma melhor visualização de certos fenômenos físicos, na medida em que torna possível a inclusão de elementos gráficos, de animações visuais, sonoras e de interações num mesmo ambiente.

Outra vantagem realçada pelos autores refere-se à economia de reagentes e materiais, evitando igualmente o lançamento de resíduos químicos nos esgotos. Além das vantagens supramencionadas, o laboratório virtual permite repetir quantas vezes quiser e rapidamente todo ou parte do procedimento experimental.

Os pesquisadores avaliam como desvantagens o fato do laboratório virtual não simular cheiros, nem permitir aos estudantes o manuseamento do material de laboratório. Sendo assim, não estimula nem avalia a destreza física para o trabalho laboratorial. Outra desvantagem apontada é a falta de treino no manuseio de equipamentos e reagentes não desenvolvendo nos alunos a atitudes de responsabilidade, prevenção e confiança. 
Na busca de soluções para a problemática citada e, atendendo à recomendação da Lei de Diretrizes e Bases da Educação Nacional (1999), deve-se investir na "alfabetização digital em todos os níveis de ensino, assim como na Química de forma abrangente e integrada, com o desenvolvimento de ferramentas químicas" mais apropriadas, apresentar-se-ão fatos concretos observáveis e mensuráveis. Isso é a que me proponho neste trabalho, a aplicação e avaliação de uma aula prática virtual sobre destilação do vinho.

\section{METODOLOGIA}

As atividades foram desenvolvidas com 39 alunos do primeiro ano do Nível Médio, de um Colégio Estadual localizado no município de Barra Mansa (RJ), A pesquisa é qualitativa, onde se utilizou como instrumento, um questionário, ocorrendo em três momentos, sendo o primeiro a aplicação pré- testes com a finalidade de diagnosticar os conhecimentos pré-existentes, o segundo, foi ministrada a aula virtual de destilação do vinho e no terceiro momento foi aplicado um pós-teste para verificar a aprendizagem dos alunos após a realização do experimento.

O primeiro questionário (pré-teste) foi aplicado aos alunos uma semana antes da realização da prática virtual, para análise dos conhecimentos prévios dos alunos. Após a realização da aula prática virtual, os pontos mais relevantes foram resgatados em forma de relatório, sendo aplicado o segundo questionário (pós-teste) para observar se os conceitos e os conhecimentos que os estudantes tinham no início, permaneciam ou se haviam mudado, a fim de verificar se houve contribuição da estratégia no aprendizado desse conteúdo.

O questionário continha 06 perguntas investigando conhecimentos dos alunos sobre a destilação do vinho que são as seguintes:

1-O que é destilação simples? 2-Quais são os componentes químicos encontrados no vinho? 3- Porque os vinhos são guardados nas adegas na vertical? 4-Quais são as conseqüências do uso abusivo do álcool? 5-Qual a temperatura que o álcool ferveu? 6Qual a função do condensador e da tela de amianto? 
O pós-teste foi aplicado uma semana após os alunos terem realizado a aula prática, onde os sendo o mesmo valendo nota final de trabalho e os dados foram compilados e representados em forma de em forma de gráficos.

\section{APRESENTAÇÃO DA AULA PRÁTICA VIRTUAL "DESTILAÇÃO DO VINHO"}

A tela de abertura (Figura 1), também chamada de tela principal, contém o roteiro com o título e o objetivo da aula. Em todas as tela contém setas indicativas para retornar ou seguir adiante.

Figura 1: Tela de abertura da destilação do vinho.

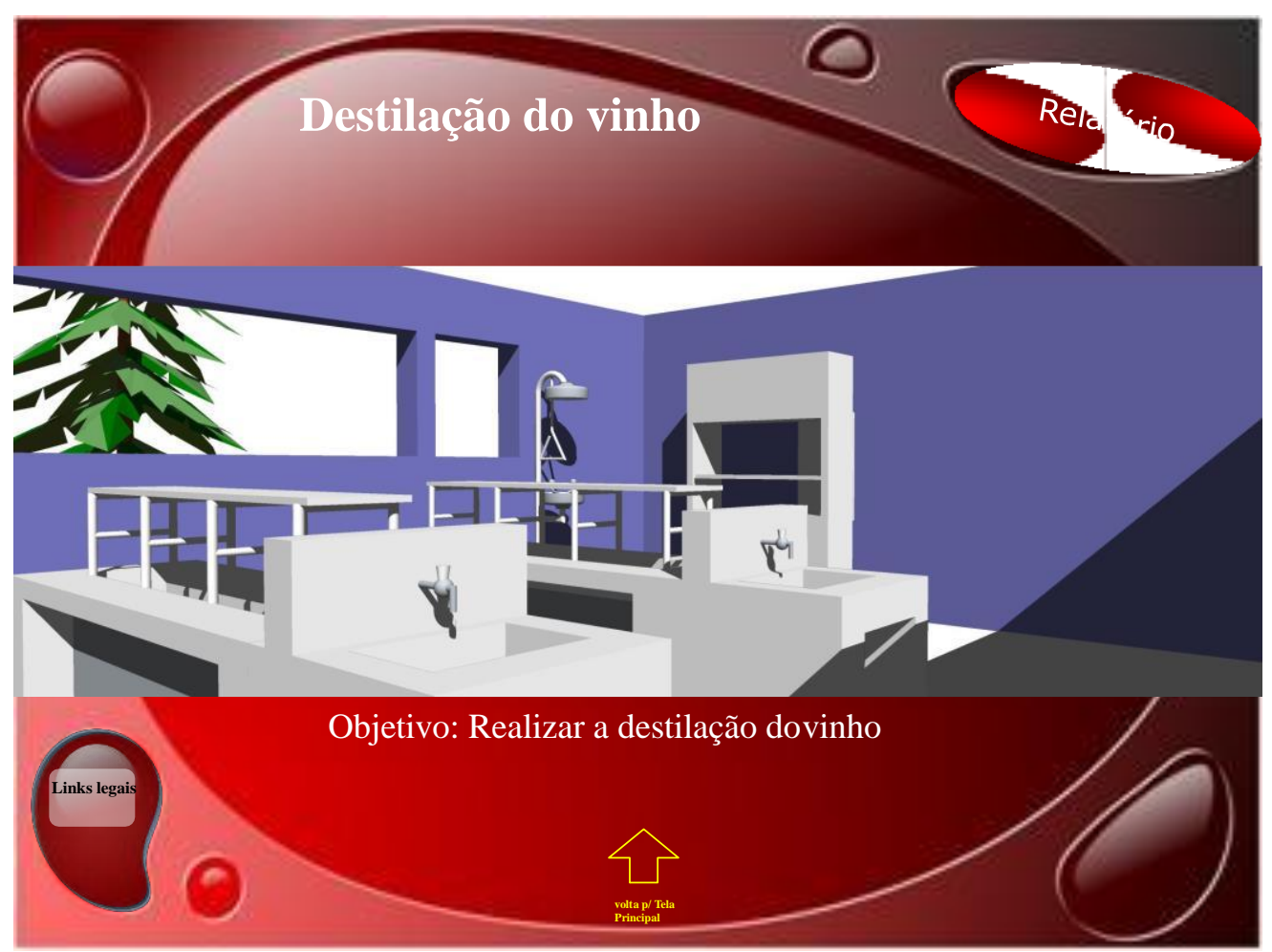


A próxima tela que se apresenta são os fundamentos teóricos (Figura 2) a respeito do vinho e do álcool.

Figura 2: Tela dos fundamentos Teóricos.

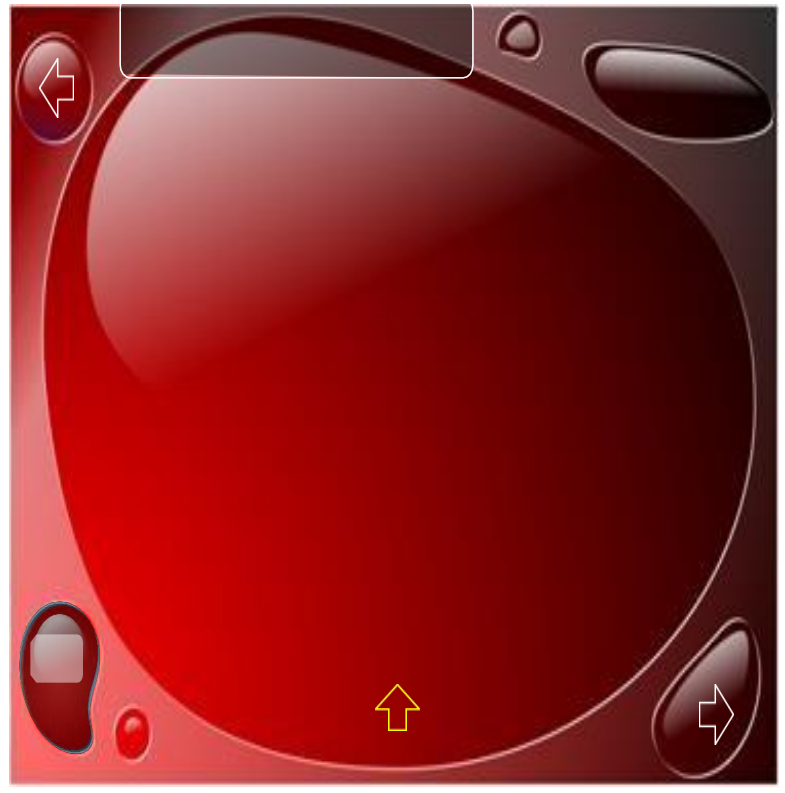

$\mathrm{Na}$ tela seguinte, o usuário depara com a simulação do experimento, indicada passo a passo, seguindo a sequência numérica destacada em cor amarela, conforme mostrado na figura (Figura 3).

Figura 3: Simulação da destilação do vinho, passo a passo. 


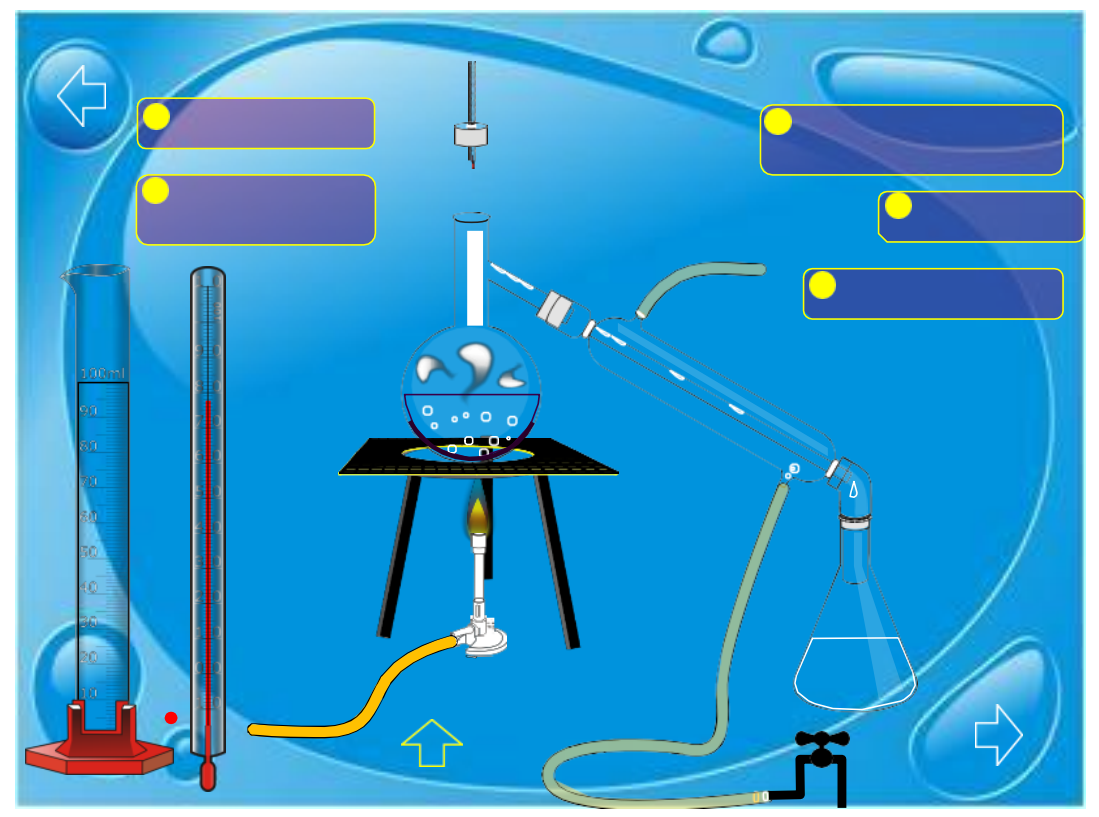

Em todas as telas há uma seta indicativa (Menu) "Volta para a tela principal, caso o estudante queira retornar à tela anterior. Também em todas as tela há links legais, caso o estudante queira acessá-lo, terá disponível uma apostila teórica sobre a destilação do vinho, assim com vídeos disponíveis como mostra a figura 4.

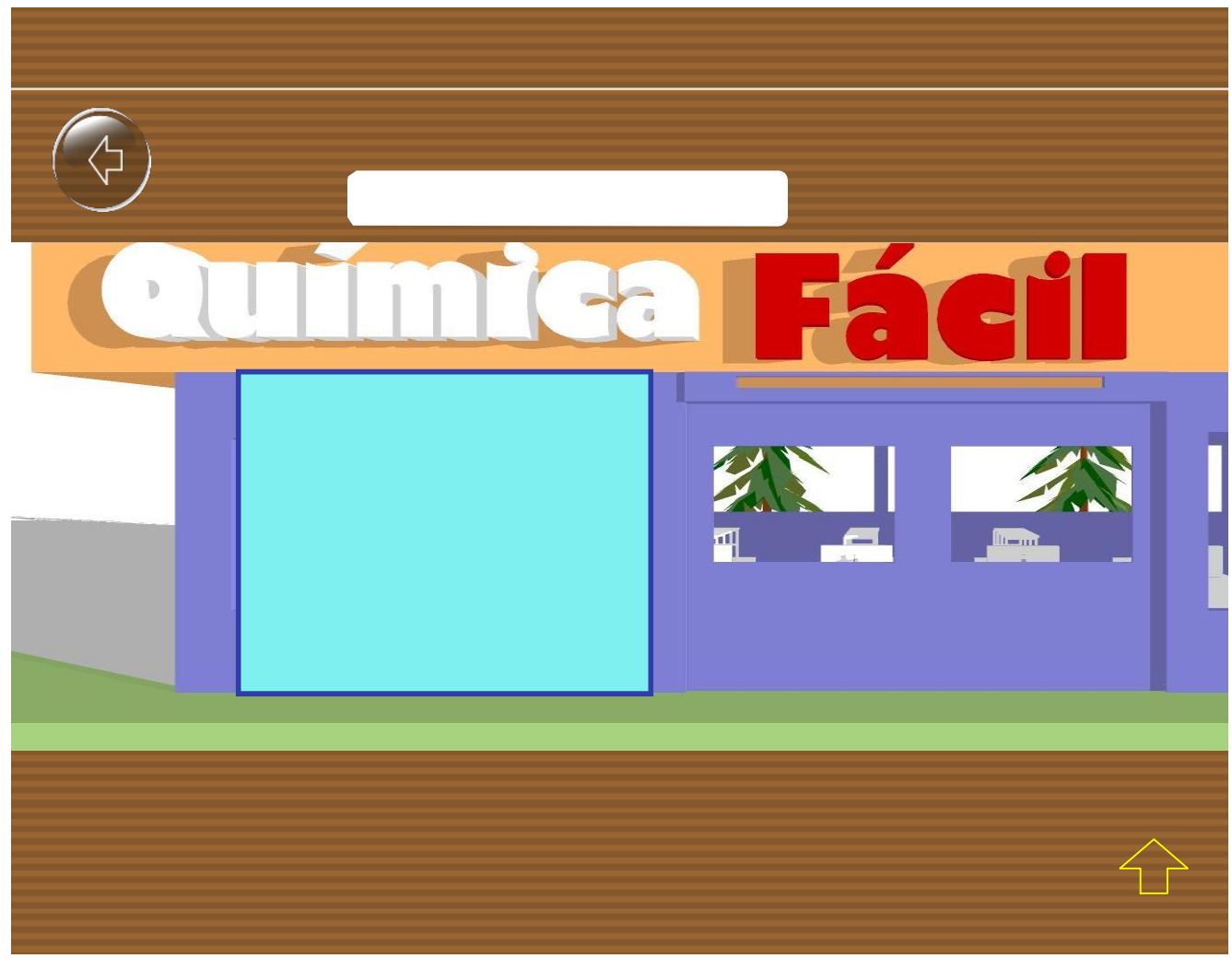

Figura 4: Tela do Vídeo de destilação do vinho. 
Em todas as telas, tem-se a opção de executar a prática ou retornar ao índice, sendo disponibilizado links para a feitura do relatório, assim como link para acesso a apostila teórica do assunto.

Após a conclusão dos experimentos, o usuário tem a opção de fazer o relatório como exemplificado na figura 5, oportunizando ao aluno rever conceito envolvido no experimento realizado, sempre que necessário, nos remetendo à memorização.

\section{RELATÓRIO-DESTILAÇÃO DO VINHO}

\begin{tabular}{|l|l|l|l||l}
\hline Nome & Número & Turma & Bancada & \\
\hline 1.Objetivos: &
\end{tabular}

2)Observações:

2.1) Qual a temperatura em que o destilado ferveu?

2.2) Qual líquido foi destilado? Como você comprovou?

2.3) Qual a função do condensador?

2.4) Qual a importância da destilação?

2.5)Relacione outras técnicas para separar componentes de misturas homogêneas

Figura 5: Modelo do Relatório da destilação do vinho 


\section{RESULTADOS E DISCUSSÕES}

Os resultados obtidos foram representados em seis gráficos (Figura 6), a seguir.

Figura 6: Resultado do questionário do pré-teste e pós-teste.

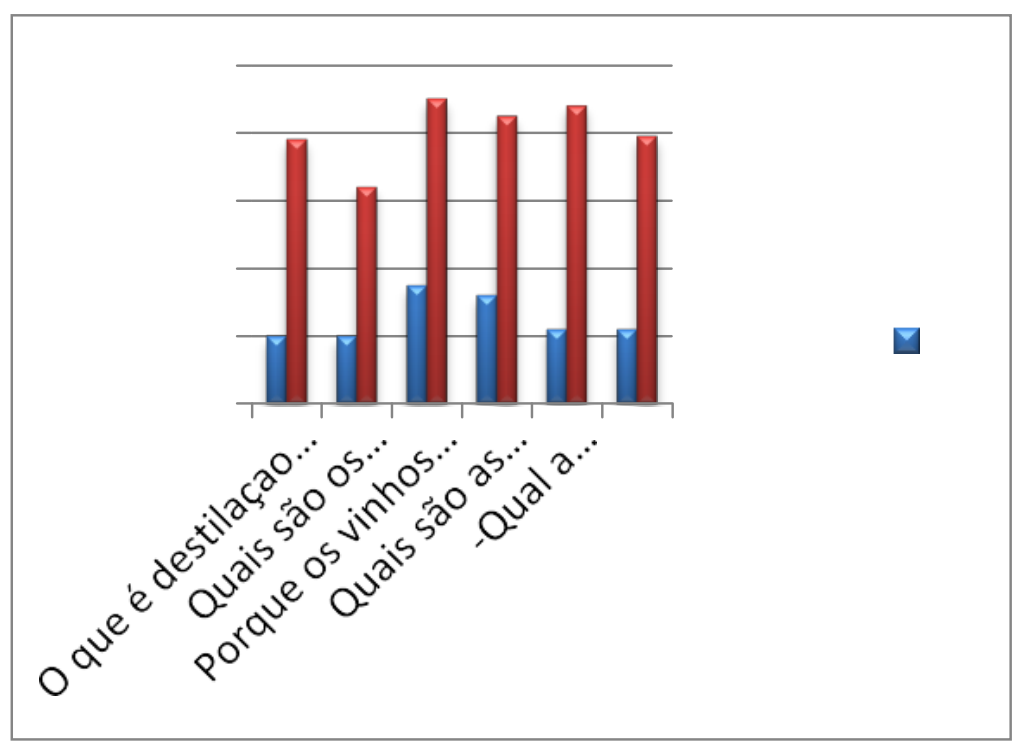

Fonte: Elaborado pelos autores (2017)

De acordo com os dados obtidos pela aplicação dos questionários, observamos que as porcentagens de acertos do pós-teste foram maiores do que do pré-teste em todos os quesitos, o que podemos inferir que o laboratório virtual é uma proposta real, de ensino-aprendizagem em Química.

Os dados revelaram também que os alunos tinham poucos conhecimentos prévios em relação à destilação do vinho, pois não houve em nenhuma questão acerto maiores que $50 \%$ no pré teste. Logo os professores de química precisam lançar um novo olhar para o ensino, dando sentido ás experiências e conceitos trazidos pelos estudantes.

Assim, o professor de química deve ser desafiador e buscar novas metodologias para que os alunos tenham uma visão da química concreta e funcional, relacionando-a com os acontecimentos diários, e nesse sentido, Silva $(2006$, p.19, 21) relata que o 
professor deve estar preparado para facilitar a compreensão e o aprendizado dos alunos para a vida atual; deve "recorrer a novas metodologias" de ensino, sempre buscando “posicionar-se em situações problemáticas e solucioná-las”.

\section{CONSIDERAÇÕES FINAIS}

Através dos dados obtidos, podemos considerar que a aula prática virtual da destilação do vinho é uma contribuição real no processo ensino- aprendizagem, auxiliando como recurso instrucional.

Consideramos que atingimos o nosso objetivo através da metodologia utilizada, pois com o pré-teste realizamos uma avaliação diagnóstica, apontando que os alunos tinham poucos conhecimentos prévios sobre o assunto, e com pós-teste, que serviu para verificar o aprendizado químico, verificamos que houve evolução dos conceitos dos alunos em relação ao assunto da destilação do vinho.

Após uma análise dos dados e das abordagens dos gráficos, averiguamos que os conceitos químicos em ambientes de realidade virtual, que possibilitem ao aluno uma direta interatividade com os assuntos abordados em sala de aula, podem tornar-se uma ferramenta de ensino e aprendizagem de grande importância. Pretendemos, também, aumentar a quantidade de simulações para compor um banco para ser utilizado em sala de aula.

Considerando que a nossa vida é Química, assinalamos que faz necessário que os professores apontem essa realidade para os alunos articulando os diversos conceitos químicos com a realidade deles.

Assim, é necessário que o professor de química tenha um novo olhar para a realidade da sociedade tecnologicamente direcionada que já se faz presente, cabendo aos educadores planejarem, executarem e avaliarem a implantação de novos meios de comunicação ao processo de ensino e aprendizagem. Logo, fica evidente que as animações interativas e o uso das aula virtuais é uma expressiva ferramenta pedagógica sendo capaz de propiciar melhoras significativas no ensino aprendizagem de Química. 


\section{Referências}

BUENO, R. de S. M., KOVALICZN R. A., O ensino de ciências e as dificuldades das atividades experimentais. Programa de Desenvolvimento Educacional do Paraná, 2008.

CARNEVALE, D. The Virtual Lab Experiment: Some Colleges Use Computer Simulations to Expand Science Offerings Online. The Chronicle of Higher Education, Vol.49, Issue: 21, 2003.

CAVAlCAnTE, D. D.; SILVA, A. F. A. Modelos didáticos de professores: Concepções de ensino aprendizagem e experimentação. XIV Encontro Nacional de Ensino de Química. Curitiba: 2008.

DEMO, Pedro. Educar pela pesquisa. Campinas, SP: Autores Associados, 1996.

FADUL, A.M. Meios de comunicação de massa e educação no Brasil: uma perspectiva crítica. Cadernos INTERCOM (4) : 30-43, out. 1982.

FREINET, C. O Método Natural. Lisboa, Estampa, 1977, p. 13-33.

GOI, M. E. J. ; SANTOS, F. M. T. Resolução de Problemas e Atividades Experimentais no Ensino de Química. UFPR, 21 a 24 de julho de 2008. Curitiba, Pr., 2008.

KRASILCHIK, M. Reformas e realidade: o caso do ensino de ciências. São Paulo em perspectiva, 14 (1), 2000.

KRASILCHIK, M., Prática de Ensino de Biologia. 4a ed. ver. E ampl., 1a reimpr. - São Paulo: Editora da Universidade de São Paulo, 2005.

KANBACH, B. A Relação com o Saber Profissional e o Emprego de Atividades Experimentais em Física no Ensino Médio: uma leitura baseada em Charlot. Londrina

Ministério da Educação. Secretaria de Educação Média e tecnológica. Parâmetros Curriculares Nacionais: ensino médio. Brasília, 1999.

NARDI, R. Questões atuais no Ensino de Ciências. São Paulo: Escrituras, 1998.
OLIVEIRA, K. D.; SANTOS, W. L. dos; SOUZA, R, C.; MOURA, R. O.; SILVA, J. F. de M. C. da; MENEZES, J.W. M.Laboratório Virtual De Química: Blender 3d Auxiliando No Ensino Da Química. Dissertação (Mestrado em Ensino de Ciências e Educação Matemática), Departamentos de Física e Matemática, UEL, Londrina-PR, 2005.

PENTEADO, R. M. R.; KOVALICZN, R. A. Importancia de materiais de laboratorio para ensinar ciencias. 2008.

RODRIGUES, G. P. A VISÃO DE ESTUDANTES DO ENSINO MÉDIO SOBRE A QUÍMICA E OS PROFISSIONAIS DE QUÍMICA. Campina Grande-PB, 2009.

RODRIGUES, J.R.; AGUIAR, M.R.P; SANTAMARIA, L.C.; SANTOS, Z.A.M. Uma Abordagem Alternativa para o Ensino da Função Álcool. Química Nova na Escola, $\mathrm{N}^{\circ}$. 12, p.20-23, 2000 .

SCHNETZLER, R.; ARAGÃO, R. M. R. Importância, sentido e contribuições de pesquisas para o ensino de Química. Química Nova na Escola, n. 1, p. 27-31, 1995.

SILVA, L. H. A.; ZANON, L. B. A experimentação no ensino de ciências. In: SCHNETZLER, R. P.; ARAGÃO, R. M. R. Ensino de Ciências: fundamentos e abordagens. Campinas, UNIMEP/CAPES, 2000.

TRINDADE，JORGE; FIOLHAIS，CARLOS. A Realidade Virtual no ensino e aprendizagem da física e da química. Gazeta de Física. Vol. 19, 1996.

VIEIRA, E. Aulas Práticas Virtuais Como Instrumento De Aprendizagem No Ensino De Química. Dissertação de Mestrado Profissional Em Ensino Em Ciências Da Saúde E Do Meio Ambiente, 2011.

YAMAMOTO, I. ; BARBETA, V. B. Simulações de Experiências como Ferramenta de Demonstração Virtual em Aulas de Teoria de Física. Revista 
Brasileira de Ensino de Física, Vol.23, no . 2, p. 215-225., 2001.

ZANON, L. B.; SILVA, L. H. A. A experimentação no ensino de ciências. In: Schnetzler, R. P.; Aragão, R. M. R. (orgs.). Ensino de Ciências:

Fundamentos e Abordagens, Piracicaba: Capes/Unimep: Piracicaba, cap. 6, p. 120-153, 2000. 
Recebido em: 25/10/2017

Aceito em: 16/11/2017

Endereço para correspondência:

Nome: Eloísa Vieira

(c) (i)

Email: eloisavieiracn@hotmail.com

Esta obra está licenciada com uma Licença Creative Commons Atribuição 4.0 Internacional. 